\title{
Germination of Pulsatilla cernua var. koreana Seeds as Influenced by Harvest Dates and Development of Seeds Analyzed by X-ray Imaging
}

\author{
Tao Yuan and Qiuying Wei \\ School of Landscape Architecture, Beijing Forestry University; Beijing \\ Laboratory of Urban and Rural Ecological Environment; Beijing Key \\ Laboratory of Ornamental Plants Germplasm Innovation and Molecular \\ Breeding; and National Engineering Research Center for Floriculture, No. \\ 35 Qinghua East Road, Haidian District, Beijing 100083, People's Republic \\ of China
}

\section{Pablo Jourdan \\ Department of Horticulture and Crop Science, Ornamental Plant Germplasm Center, Ohio State University, Columbus, OH 43210}

\section{Yong Kwon Yoo \\ Department of Horticultural Science, College of Natural Science, Mokpo National University, Muan-Gun, Jeonnam 58854, Korea}

Additional index words. cold treatment, dormancy, empty seeds, full seeds, maturity, seed viability, X-ray scanning

\begin{abstract}
Pulsatilla cernua var. koreana seeds were harvested at six different dates between 16 days after flowering (DAF) (8 Apr.) and 43 DAF (5 May) in 2018 and categorized into six groups based on $\mathrm{X}$-ray images. Germination tests were performed without and with 2 weeks of moist $5{ }^{\circ} \mathrm{C}$ treatment [cold stratification (CS)]. Seeds harvested at 38 DAF (30 Apr.) with well-developed vegetative organs (embryo and endosperm) in seeds categorized as $A$ and $B$ (seed $A$ and seed $B$, respectively) based on the $\mathrm{X}$-ray images were considered fully developed, and $80 \%$ of seeds were considered mature. However, the germination rates were less than $26 \%$ or $28 \%$ when full seeds harvested at 43 DAF received no or 14 days of CS treatment, respectively. Our study suggests that the low germination rate of fully developed seeds as judged by $\mathrm{X}$-ray images showing well-developed embryo and endosperm could result from the presence of dormancy that was not broken effectively by 14 days of CS coupled with the loss of viability caused by 8 months of dry storage at $5{ }^{\circ} \mathrm{C}$.
\end{abstract}

Pulsatilla cernua var. koreana (Y. Yabe ex) Nakai ex T. Mori (http://www.ipni.org/ ipni/idPlantNameSearch.do?id=711999-1; accessed 17 Dec. 2020) is a perennial growing in sandy and nonfertile soil in Korea and northern parts of China. After flowering in

Received for publication 5 Jan. 2021. Accepted for publication 31 Jan. 2021.

Published online 16 March 2021

This research was funded by the Special Fund for Beijing Common Construction Project, the World-Class Discipline Construction and Characteristic Development Guidance Funds for Beijing Forestry University (2019XKJS0324), and the Beijing Landscaping Color Extension Green Science and Technology Innovation Project: Study on the technology of efficient propagation and cultivation and maintenance of garden plants in Beijing (2019-KJC-02-10).

T.Y. is the corresponding author. E-mail: yuantao@ bjfu.edu.cn.

This is an open access article distributed under the CC BY-NC-ND license (https://creativecommons. org/licenses/by-nc-nd/4.0/). approximately mid to late March, the flower head dries out, seed heads are developed, and seeds with filaments are formed; then, seeds are easily detached from the seed head, expelled by wind, and dispersed.

Pulsatilla cernua var. koreana seeds germinate within $14 \mathrm{~d}$ at $25{ }^{\circ} \mathrm{C}$; however, germination rates decrease after 6 to 8 weeks, and seeds do not germinate after 14 weeks of storage under unspecified room conditions (Sang et al., 1993). Germination rates of the fresh $P$. cernua var. koreana seeds have been reported as $63.5 \%$ (Sang et al., 1993) and $94.8 \%$ (Sang et al., 1996); however, the rates continued to decrease to $0.3 \%$ within 14 weeks (Sang et al., 1993) and 1.0\% within 24 weeks (Sang et al., 1996) of storage under room conditions. Seeds stored in moist vermiculite did not germinate at all after 24 weeks of storage (Sang et al., 1996). Low germination rates may also result from the inclusion of nonviable seeds, incomplete development of vegetative organs [embryo and endosperm (empty seed)] (Esau, 1965), and damaged vegetative organs (Yuan et al., 2019).
Because of the presence of numerous trichomes developed on the seedcoat of Pulsatilla seeds (Yuan et al., 2019), Pulsatilla seeds immersed in water to separate full, viable seeds with developed vegetative organs (full seed) from empty, nonviable seeds, as demonstrated in Corylopsis coreana Uyeki seeds (Kim et al., 2017, 2018), could not be evaluated. X-ray imaging may be useful to distinguish full seeds from empty seeds on a large scale, to evaluate images of seeds, to assess seed development, and to improve seed lot quality and germination (Carvalho et al., 2010; Kim et al., 2017, 2018; Yuan et al., 2019). Low germination rates could result from harvesting immature seeds that cannot be verified by visual observation but can be detected by X-ray imaging (Kim et al., 2017, 2018; Yuan et al., 2019) and magnetic resonance imaging, which can be used to study the internal seed structure to determine the time of harvest of mature seeds as reported for Styrax japonicus (Roh et al., 2004).

Seed dormancy could be a factor for low germination rates if dormancy is present in the mature seeds and is not released by CS or plant growth regulator treatments, especially with gibberellin (Baskin and Baskin, 2004; Cadman et al., 2006; Yuan et al., 2019). Beyond the presence of dormancy in seeds, low germination rates could result from the immaturity of seeds that were harvested prematurely after flowering that are not viable and fail to germinate.

The objectives of this research were as follows: 1) to harvest Pulsatilla cernua var. koreana seeds at different development stages after flowering; 2) to document the proportion of empty and full seeds to understand the proper stages for harvesting seeds using X-ray images to categorize seeds as empty or full; and 3) to examine the germination of these seeds with and without CS treatment.

\section{Materials and Methods}

Plant material and seed germination test. P. cernua var. koreana seeds were collected at the nursery located at Koheung-Kun, Jeonnam Province, Korea, from a group of plants that reached flowering within a 3- to 5d period on 23 Mar. 2018. Seeds harvested on 8, 15, 20, 25, and 30 Apr. 2018 and on 5 May $2018(16,23,28,33,38$, and $43 \mathrm{DAH}$, respectively) (Fig. 1) were packed in a paper bag filled with silica gels and placed in plastic bags with locking seals; then, they were stored dry at $5{ }^{\circ} \mathrm{C}$. Seeds were mailed to Beijing Forestry University (Beijing, China) on 23 Aug. and stored dry at $5{ }^{\circ} \mathrm{C}$ in silica gels until 26 Nov. 2018.

Seeds were stored either dry or after mixing with $50 \%$ moisture sands at $5{ }^{\circ} \mathrm{C}$ for $14 \mathrm{~d}$ in CS. All seeds were sown on open trays filled with peat:vermiculite (1:1 by volume) on 12 Dec. 2018 , and watered every other day. Germination was recorded daily at $20^{\circ} \mathrm{C}$ under cool white fluorescent tubes with a photosynthetic photon flux density of 75 $\mu \mathrm{mol} \cdot \mathrm{m}^{-2} \cdot \mathrm{s}^{-1}$. There were 100 seeds per 

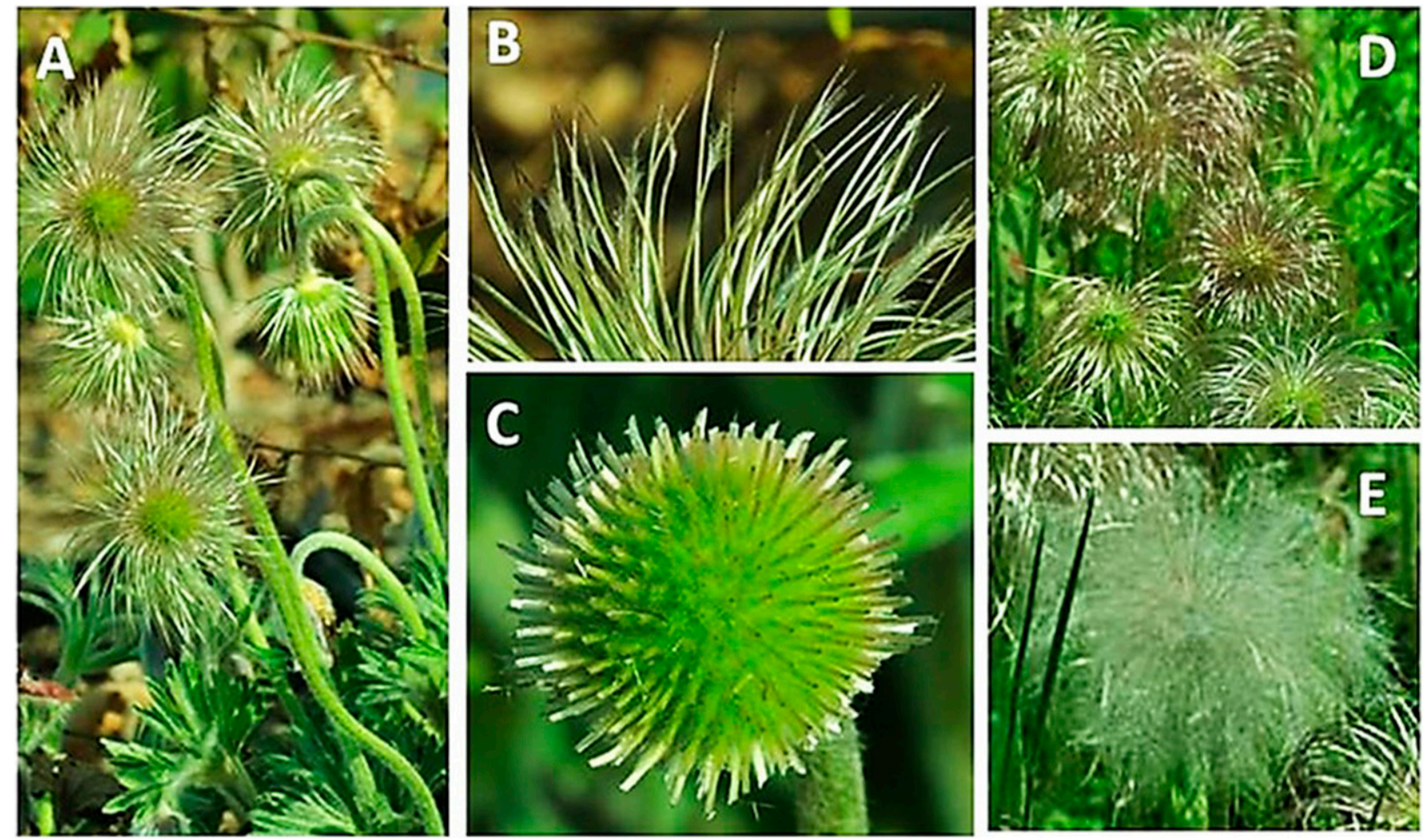

Fig. 1. Development of flower head after flowering on 23 Mar. 2018, with numerous filaments of $P$. cernua var. koreana. (A) Most flower heads were still bent. (B) The tips of the filaments started to split. (C) Filaments were cut off, leaving $\approx 2-3 \mathrm{~cm}$ at the proximal end. (D) Flower heads are pointing upward, with some filaments turning white. (E) All filaments of most flower heads became mature and were ready to be separated from the flower head.

replication and three replications per harvest date, which were all randomized during the seed germination test.

Two sets of 50 randomly selected seeds for each harvest date were glued to the card $(5 \times 7.5 \mathrm{~cm})$ and mailed to the Ornamental Plant Germplasm Center (Ohio State University, Columbus, $\mathrm{OH}$ ) for X-ray scanning on 17 Feb. 2019, as described previously (Kim et al., 2018). After X-ray scanning, seeds were mailed to Beijing Forestry University and germinated as described. During the period when seeds were in the mail $(7 \mathrm{~d}$ when mailed to Beijing Forestry University and $11 \mathrm{~d}$ when they mailed from the Ornamental Plant Germplasm Center), temperature and other environment factors could not be monitored.

Classification of seeds based on X-ray images. Seeds were classified into the following categories (Fig. 2).

Data collection and analysis. Seed germination was recorded daily for $35 \mathrm{~d}$ after hypocotyl emerged from the sowing medium. The number of days to germination of the first seed was counted from the sowing date, the final germination rate was obtained, the $50 \%$ germination rate, and the final germination rate was tabulated. The mean and SD of three replications per treatment are presented. Data were analyzed by a two-way analysis; harvest dates and seed classification by X-ray images were the two main variables. Means were compared by Duncan's multiple range test with IBM
SPSS Statistics for Windows (version 20.0 software; IBM Corp., 2011).

\section{Results and Discussion}

Development of inflorescence and visual observation of seeds. Fifty plants reached flowering on 23 Mar. 2018, and seeds were collected from $\approx 10$ to 15 inflorescences at each harvest date. On 8 Apr. (16 DAF), inflorescences pointed downward (pendulous) (Fig. 1) and with most of flower stalk supporting floral organ were still bent; however, some started to point up 23 DAF (Fig. 1A). On 20 Apr. (28 DAF), the flower stalk pointing upward straightened upward and all petals were dehisced from the receptacle; the remaining filaments with a tip started to split (Fig. 1B) before turning to whitish, and the distal ends of the filaments were cut off (Fig. 1C). On 25 Apr. (33 DAF), the distal ends of the filaments turned white and started to become puffy (Fig. 1D). On 30 Apr. (38 DAF) and 5 May (43 DAF), all filaments became puffy (Fig. 1E); the seeds were easily separated from the receptacle and dispersed readily by wind.

Based on visual observations described previously (Figs. 1 and 2 in Yuan et al., 2019), full seeds are round, enlarged, and dark brown at the midpoint and along the longitudinal axis (from the proximal end to the distal end). These are considered mature, have developed vegetative organs, and are likely to germinate. Fewer than 28\% seeds are considered full when harvested on or before 28 DAF, when flower heads are bent and pointing down (Table 1).

When flower heads started to point upward and the tip of the filaments became puffy at 33 DAF (Fig. 2D), 57\% of seeds were evaluated and considered full. When harvested on or after $38 \mathrm{DAF}$, more than $75 \%$ of seeds were full. This phenomenon (i.e., flower head pointing upward, which was observed between 28 and 33 DAF in our study) could result from pollination followed by the development of seeds (Huang et al., 2002).

Full seeds with well-developed vegetative organs (Esau, 1965; Yuan et al., 2019) had higher germination rates than empty seeds. Using light microscopy or the naked eye to visually separate full seeds from empty seeds is a time-consuming process and may not result in accurate evaluations of the development of vegetative organs.

Relationship between harvest dates and $X$-ray images of seeds. Visually observing the external morphology of seed does not accurately reveal the development of seeds; therefore, X-ray imaging should be considered when evaluating the germination rates, as reported for Pulsatilla (Yuan et al., 2019) and Corylopsis (Kim et al., 2017, 2018). Xray imaging analysis, which does not produce detailed internal seed structures on a large scale, as reported for Corylopsis (Kim et al., 2018), compared with magnetic resonance imaging (MRI), as reported for 
A
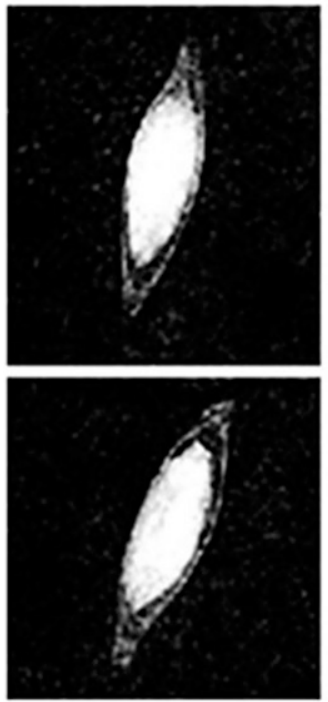

B
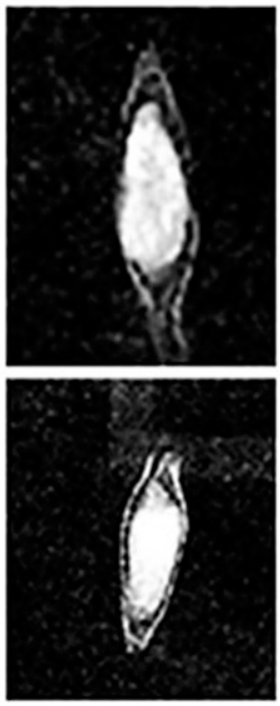

C
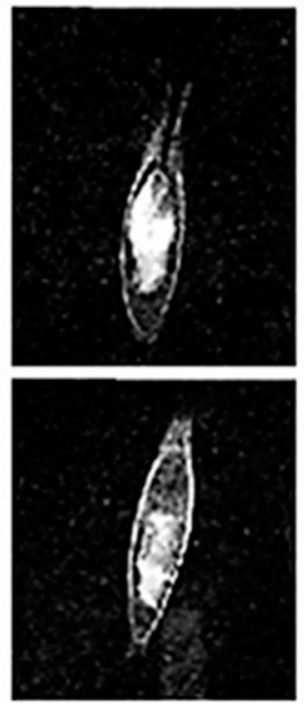

D
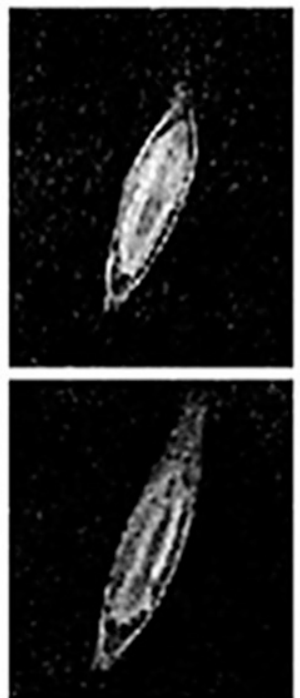

E
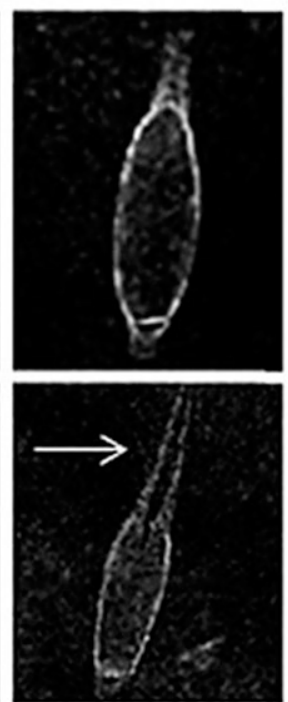

F
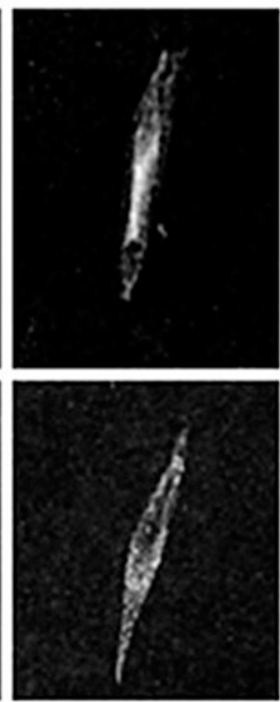

Fig. 2. Classifications of seeds ranging from full (A) to empty (E) of P. cernua var. koreana seeds based on the X-ray images. (A) Full seeds with well-developed vegetative organs. (B) Full seeds with incomplete development of vegetative organs. (C) Greater degree of progression of incomplete vegetative organs. (D) Degenerated vegetative organ. (E) Round seeds with an empty center. (F) Seeds withered with severely degenerated vegetative organs. The filament attached to the achene is indicated by the arrow in the lower frame of $\mathbf{E}$.

Styrax (Roh et al., 2004), is considered useful for differentiating immature (empty) seeds from mature (full) seeds on a large scale. For Corylopsis, immersing seeds in water to separate full seeds from empty seeds has been found effective. However, for Pulsatilla, because of the presence of trichomes on the surface of seeds (Yuan et al., 2019), immersing seeds could not separate full seeds from empty seeds. Huang et al. (2002) mentioned that the petal of $P$. cernua was also covered with trichomes, which repel water from the flower to allow pollen to dry and maintain its viability to facilitate pollination.

Images of two seeds classified as seed A (full seeds) or seed E (empty seeds) are presented (Fig. 2). Most seeds harvested 16 DAF were empty and most seeds harvested 43 DAF were full; more full seeds than empty seeds were harvested $28 \mathrm{DAF}$ and $33 \mathrm{DAF}$ (Table 2). Because the number of seed $\mathrm{C}$ was significantly reduced to less than 5.0 when seeds were harvested 33 DAF, seeds harvested in bulk could be delayed to 33 DAF. To ensure the harvest of mostly full mature seeds, it is suggested that seeds should be harvested 43 DAF. Seed A is full and mature and is considered to germinate when dormancy is broken by sufficient CS. Seed E is empty, without vegetative organs, and will not germinate even with sufficient CS. Seed B has well-developed vegetative organs, but both ends of the seeds have some spaces that may or may not be able to germinate. Seed C may have less developed or aborted vegetative organs that may require an after-ripening period. Regardless of the seed harvest dates, some seeds belonged to categories D and E,

Table 1. Germination of Pulsatilla cernua var. koreana seeds as influenced by harvest dates and $5{ }^{\circ} \mathrm{C}$ cold treatment.

\begin{tabular}{|c|c|c|c|c|c|c|c|c|c|}
\hline \multirow[b]{2}{*}{$\begin{array}{l}\text { Seed harvest } \\
\text { date (2018) }\end{array}$} & \multirow[b]{2}{*}{$\begin{array}{l}\text { Days after } \\
\text { flowering }\end{array}$} & \multirow[b]{2}{*}{$\begin{array}{c}\text { Weeks with } \\
5^{\circ} \mathrm{C} \text { treatment }\end{array}$} & \multicolumn{2}{|c|}{ Days to: } & \multirow{2}{*}{$\begin{array}{c}\text { Final } \\
\text { germination } \\
\text { rate }(\%)\end{array}$} & \multirow[b]{2}{*}{$\begin{array}{c}\text { Weeks with } \\
5^{\circ} \mathrm{C} \text { treatment }\end{array}$} & \multirow[b]{2}{*}{$\begin{array}{l}\text { First seed } \\
\text { germinated }\end{array}$} & \multirow[b]{2}{*}{$\begin{array}{c}\text { Final } \\
\text { germination }\end{array}$} & \multirow{2}{*}{$\begin{array}{c}\text { Final } \\
\text { germination } \\
\text { rate }(\%)\end{array}$} \\
\hline & & & $\begin{array}{l}\text { First seed } \\
\text { germinated }\end{array}$ & $\begin{array}{c}\text { Final } \\
\text { germination }\end{array}$ & & & & & \\
\hline 8 Apr. & 16 & 0 & $-\mathrm{y}$ & - & - & 2 & - & - & - \\
\hline 15 Apr. & 23 & 0 & - & - & - & 2 & - & - & - \\
\hline 20 Apr. & 28 & 0 & - & - & - & 2 & - & - & - \\
\hline 25 Apr. & 33 & 0 & $15 \pm 1.4^{\mathrm{x}}$ & $24 \pm 1.6$ & $4 \pm 0.5$ & 2 & $14 \pm 0.5$ & $22 \pm 2.1$ & $6 \pm 1.6$ \\
\hline 30 Apr. & 38 & 0 & $17 \pm 0.5$ & $25 \pm 2.9$ & $3 \pm 1.4$ & 2 & $17 \pm 1.3$ & $22 \pm 0.8$ & $5 \pm 0.5$ \\
\hline 5 May & 43 & 0 & $17 \pm 1.3$ & $26 \pm 2.6$ & $6 \pm 0.5$ & 2 & $12 \pm 1.6$ & $28 \pm 0.8$ & $21 \pm 0.5$ \\
\hline
\end{tabular}

${ }^{\mathrm{z}}$ Flowering occurred on 23 Mar. 2018.

${ }^{\mathrm{y}}$ Seeds did not germinate or the germination percentage was less than $3 \%$ for all replications. The mean and sD were not calculated.

${ }^{\mathrm{x}}$ Mean \pm SD of three replications at each harvest date, with 100 seeds per replication.

Table 2. Germination of Pulsatilla cernua var. koreana seeds harvested at different times after flowering based on X-ray imaging.

\begin{tabular}{|c|c|c|c|c|c|c|c|c|c|c|c|}
\hline \multirow{2}{*}{$\begin{array}{l}\text { Seed harvest } \\
\text { date }(2018)\end{array}$} & \multirow{2}{*}{$\begin{array}{l}\text { Days after } \\
\text { flowering }\end{array}$} & \multicolumn{5}{|c|}{ Total seeds assigned to categories based on X-ray imaging ${ }^{\mathrm{y}}$} & \multicolumn{5}{|c|}{ Percentage of seeds germinated in each category ${ }^{\mathrm{y}}$} \\
\hline & & A & $\mathrm{B}$ & $\mathrm{C}$ & $\mathrm{D}$ & $\mathrm{E}$ & A & $\mathrm{B}$ & $\mathrm{C}$ & $\mathrm{D}$ & $\mathrm{E}$ \\
\hline 8 Apr. & 16 & $0.5 \mathrm{~h}^{\mathrm{x}}$ & $3.0 \mathrm{fgh}$ & $12.0 \mathrm{~d}-\mathrm{h}$ & $20.0 \mathrm{bcd}$ & $14.5 \mathrm{c}-\mathrm{f}$ & $0 \mathrm{~d}$ & $0 \mathrm{~d}$ & $0 \mathrm{~d}$ & $0 \mathrm{~d}$ & $0 \mathrm{~d}$ \\
\hline 15 Apr. & 23 & $2.0 \mathrm{fgh}$ & $5.0 \mathrm{e}-\mathrm{h}$ & $20.0 \mathrm{bcd}$ & $13.0 \mathrm{~d}-\mathrm{h}$ & 8.0 d-h & $0 \mathrm{~d}$ & $0 \mathrm{~d}$ & $0 \mathrm{~d}$ & $0 \mathrm{~d}$ & $0 \mathrm{~d}$ \\
\hline 20 Apr. & 28 & $13.5 \mathrm{cf}$ & $12.0 \mathrm{dh}$ & $17.0 \mathrm{cde}$ & $5.5 \mathrm{e}-\mathrm{h}$ & $2.0 \mathrm{fgh}$ & $2.9 \mathrm{~cd}$ & $5 \mathrm{~cd}$ & $0 \mathrm{~d}$ & $0 \mathrm{~d}$ & $0 \mathrm{~d}$ \\
\hline 25 Apr. & 33 & $25.0 \mathrm{abc}$ & $12.0 \mathrm{dh}$ & $5.0 \mathrm{e}-\mathrm{h}$ & $2.5 \mathrm{fgh}$ & $5.5 \mathrm{e}-\mathrm{h}$ & $24.0 \mathrm{~b}$ & $7.1 \mathrm{~cd}$ & $0 \mathrm{~d}$ & $0 \mathrm{~d}$ & $0 \mathrm{~d}$ \\
\hline 30 Apr. & 38 & $32.0 \mathrm{a}$ & $8.0 \mathrm{~d}-\mathrm{h}$ & $3.5 \mathrm{fgh}$ & $2.0 \mathrm{fgh}$ & $4.5 \mathrm{fgh}$ & $31.0 \mathrm{ab}$ & $7.1 \mathrm{~cd}$ & $0 \mathrm{~d}$ & $0 \mathrm{~d}$ & $0 \mathrm{~d}$ \\
\hline 5 May & 43 & $30.5 \mathrm{ab}$ & $10.0 \mathrm{~d}-\mathrm{h}$ & $5.5 \mathrm{e}-\mathrm{h}$ & $2.5 \mathrm{fgh}$ & $1.5 \mathrm{gh}$ & $38.1 \mathrm{a}$ & $10.0 \mathrm{c}$ & $5.6 \mathrm{~cd}$ & $0 \mathrm{~d}$ & $0 \mathrm{~d}$ \\
\hline
\end{tabular}

${ }^{\mathrm{z}}$ Flowering occurred on 23 Mar. 2018.

${ }^{\mathrm{y}}$ The mean of two replications at each harvest date and 50 seeds per replication. Percentage of seeds germinated/the total number of seeds assigned to categories based on X-ray imaging. Refer to Fig. 2 for categories of seeds [from A (full seeds) to E (empty seeds)] based on X-ray images.

${ }^{\mathrm{x}}$ Mean comparison using Duncan's multiple test at $P \leq 0.05 \%$ (F-test). Means with different letters within a column are significantly different from each other. 
which are empty; these seeds did not germinate (Table 2).

Germination rates in relation to harvest dates and X-ray imaging of seeds. Seeds harvested 16, 23, and 28 DAF failed to germinate even with $14 \mathrm{~d}$ of CS treatment (Table 1). These seeds are considered not dormant and did not respond to 4 weeks of CS (Yuan, et al., 2019). These immature seeds cannot be forced to mature by being placed in moist conditions and allowed to dry slowly (Baskin et al., 2006). These empty seeds are lacking vegetative organs when harvested on or before 28 DAF. They start to mature when harvested on or after $33 \mathrm{DAF}$, although the germination rate is less than $6 \%$ with $\mathrm{CS}$ treatment. Some of these seeds can be considered physiologically immature and developing from immature to mature (semimature seeds); these seeds may require more than $14 \mathrm{~d}$ of CS. Because of the limitation of seeds, it was not possible to provide longer than $14 \mathrm{~d}$ of CS or treatment with gibberellin, as was performed previously (Yuan et al., 2019). Perhaps maturity could be induced if semimature seeds are subjected to alternating high and low temperature treatments, as reported for Collinsonia canadensis and Dioscorea villosa, because warm temperature treatments induce the development of embryos and low temperature treatments break dormancy (Albrecht and McCarthy, 2006).

When seeds were harvested 43 DAF (5 May) and received $14 \mathrm{~d}$ of CS, the first seed germinated within $12 \mathrm{~d}$ (the earliest) and continued to germinate, reaching final germination (rate of $21 \%$ ) at $28 \mathrm{~d}$; without 2 weeks of CS, it took $17 \mathrm{~d}$ for the first seeds to germinate, reaching final germination (rate of $6 \%$ ) at $26 \mathrm{~d}$ (Table 1). The final germination rates $(6 \%$ without $C S$ and $21 \%$ with $\mathrm{CS})$ when harvested 43 DAF were significantly lower than those ( $77 \%$ to $86 \%$ ) previously reported (Sang et al., 1993, 1996). The germination rate of seeds that were stored in silica gels at $5{ }^{\circ} \mathrm{C}$ between the last seed harvest date ( 5 May) and the date when experiments were started (Nov. 26; $\approx 26$ weeks) was similar to that $(22 \%)$ when seeds were stored moist either at 0 or $10{ }^{\circ} \mathrm{C}$ (Sang et al., 1996); however, the germination rates were $0.3 \%$ higher when seeds were stored for 14 weeks (Sang et al., 1993 ) and $1 \%$ higher when seeds were stored for 24 weeks (Sang et al., 1996). It is not clear whether low germination rates could be attributed to the inclusion of immature seeds or the presence of dormancy that is not completely broken by 2 weeks of $\mathrm{CS}$ or extended storage at $5{ }^{\circ} \mathrm{C}$ after harvest (10 May-12 Dec. 2018).

When harvesting occurred on or after 33 DAF, 25 seeds were seed A, 12 seeds were seed $\mathrm{B}, 5$ seeds were seed C, 2.5 seeds were seed D, and 5.5 seeds were seed E (Table 2, Fig. 2). Based on the number of seed $A$ and seed $\mathrm{B}$, fully developed seeds can be harvested 43 DAF. However, the germination rates of seed A and seed B were less than $38 \%$ and $8 \%$, respectively. The combined germination rate for seed A plus seed B is nearly $21 \%$ (Table 2). Based on a previous report of
P. cernua var. koreana, if all or most fully developed seed A or seed B germinate after 2 weeks of CS, then more than 40 to 50 seeds harvested 38 and 43 DAF may germinate (Sang et al., 1993, 1996; Yuan et al., 2019).

Possible causes of low germination rates of full and mature seeds. Because all full seeds did not germinate, perhaps because of the presence of dormancy, the germination rate used to assess the dormancy may be based on the number of full seeds (seed A) and perhaps semi-full seeds (seed B). It is not clear why the germination rate of fully developed mature seeds with well-developed vegetative organs based on X-ray images in this study was less than $38 \%$ for seeds harvested 43 DAF during this study and $72 \%$ during a previous study with the same temperature conditions (Yuan et al., 2019). This may indicate that dormancy, whether shallow or deep physiological dormancy (Baskin and Baskin, 2004), might not have been broken by 2 weeks of CS, and additional CS may be needed, as observed for Corylopsis coreana (Kim et al., 2017). Perhaps warm stratification and CS may be required for embryo growth and to break seed dormancy (Baskin and Baskin, 2014).

Further research is required to understand why the germination rate of mature seeds, especially with seed A with well-developed vegetative organs, in this study was lower than previously reported rates (Sang et al., 1993, 1996). Based on the germination of seeds classified by X-ray images, seed A (full seeds) in this study and a previous study (Yuan et al., 2019) were mature seeds that were attached to the mother plant with welldeveloped vegetative organs because harvest dates were delayed and were considered dormant but could germinate when environment factors were favorable. However, the germination temperature $\left(20^{\circ} \mathrm{C}\right.$ in this study) may be lower than $25^{\circ} \mathrm{C}$ for $P$. cernua var. koreana (Sang et al., 1993) and 25 to $30{ }^{\circ} \mathrm{C}$ for $P$. turczaninovii seeds when the seed age and storage conditions are unknown (Wang et al., 2013).

The germination temperature tested during this study $\left(20^{\circ} \mathrm{C}\right)$ may not be optimal. To find the optimum temperature for Pulsatilla seed germination, temperatures ranging between 20 and $35{ }^{\circ} \mathrm{C}$ should be evaluated (Baskin et al., 2006). Unfortunately, because of the limited availability of growth chambers and the number of seeds, temperatures higher than $20^{\circ} \mathrm{C}$ could not be tested (Yuan et al., 2019).

Viability might have been reduced by the long period of storage in this study. Viability was more than $0.3 \%$ when seeds were stored for 14 weeks (Sang et al., 1993) and 1\% when seeds were stored for 24 weeks (Sang et al., 1996). It has been speculated that the viability of seed A and seed B may have been affected by unfavorable environments when they were mailed to China for germination testing (Table 1) or when they were mailed to the United States and then back to China for $\mathrm{X}$-ray imaging. It is possible that the failure of immature seeds (seed C) to germinate was not related to the loss of their viability, especially those harvested on or before 38 DAF; however, it could have been attributable to their immaturity resulting from undeveloped vegetative organs. For seed D, their viability and dormancy may not have caused their failure to germinate, and maturation of their vegetative organs may have been completed or aborted at harvest, leading to empty seeds. Yuan et al. (2019) reported that the germination rates of seeds stored dry for 44 weeks decreased from $52.6 \%$ to $26.3 \%$ to $29.7 \%$ because of the presence of dormancy, damage to the vegetative organs (especially the embryo), loss of viability in mature or premature seeds, or the presence of nickel in the seeds (Yuan et al., 2019).

Classification of dormancy in Pulsatilla seeds: shallow to intermediate physiological dormancy. Because less than $10 \%$ of seed B and $6 \%$ of seed $\mathrm{C}$ germinated, seed $\mathrm{B}$ or seed $\mathrm{C}$ may have other physiological characteristics influencing germination in addition to dormancy present in seed A. The dormancy of Pulsatilla should be further investigated to determine whether it is deep or shallow, whether it is completely broken because of variances among seeds, and whether long or short periods of CS treatment are required (Baskin and Baskin, 2014). Seeds were immersed in water for $24 \mathrm{~h}$ to perform dissection without any difficulties observing the presence of vegetative organs; therefore, physical dormancy may not have been present (Nikolaeva et al., 1973).

Based on this study, it may not be feasible to classify Pulsatilla seeds as deep dormant seeds. Nikolaeva et al. (1973) stated that deep dormant seeds require two stages of temperatures, 9 to $10{ }^{\circ} \mathrm{C}$ and 0 to $3{ }^{\circ} \mathrm{C}$, and that gibberellin can be substituted during the first phase of germination. The dormancy of Pulsatilla (Ranunculales) is classified as type 2, nondeep, physiological dormancy, whereby germination is favored by lower temperature ranges (Baskin and Baskin, 2014); however, its dormancy could be classified as less than intermediate physiological dormancy because seeds does not require 2 to 3 months of CS, as summarized by Baskin and Baskin (2004). Further studies are required to understand whether other factors, such as after-ripening and requiring sequential cold-warm-cold treatment, as reported for Collinsonia canadensis (Lamiaceae) and Dioscorea villosa (Dioscoreaceae (Albrecht and McCarthy, 2006), can improve germination.

\section{Conclusions}

Fully developed seeds harvested on or after $38 \mathrm{DAF}$, when filaments are turning white and some filaments are turning puffy, are considered mature and able to germinate. However, $14 \mathrm{~d}$ of $5{ }^{\circ} \mathrm{C} \mathrm{CS}$ is not sufficient to break dormancy and increase germination rates. X-ray imaging can effectively separate full and mature seeds from empty seeds. Germination rates of full seeds (seed A) were higher than those of semi-full seeds (seed B 
and seed C). However, germination rates of full and semi-full seeds in this study were low, perhaps because of long-term seed storage (even at $5{ }^{\circ} \mathrm{C}$ ), which could induce the loss of viability and low germination temperatures. Therefore, more extensive research should be performed to determine the most effective dormancy-breaking treatments to increase germination rates, such as higher germination temperatures, longer treatment at $5{ }^{\circ} \mathrm{C}$, alternating temperature treatments (such as low-high-low temperature treatment), and various treatment methods involving plant growth regulators.

\section{Literature Cited}

Albrecht, M.A. and B.C. McCarthy. 2006. Seed germination and dormancy in the medicinal woodland herbs Collinsonia canadensis L. (Lamiaceae) and Dioscorea villosa L. (Dioscoreaceae). Flora 201(1):24-31, doi: 10.1016/j.flora.2005.04.001.

Baskin, C.C. and J.M. Baskin. 2014. Seeds: Ecology, biogeography, and evolution of dormancy and germination, p. 24-47. Types of seed dormancy. Academic Press, an imprint of Elsevier, San Diego, CA.

Baskin, J.M. and C.C. Baskin. 2004. A classification system for seed dormancy. Seed Sci. Res. 14:1-16, doi: 10.1079/SSR2003150.
Baskin, C.C., K. Thompson, and J.M. Baskin. 2006. Mistakes in germination ecology and how to avoid them. Seed Sci. Res. 16:165168, doi: 10.1079/SSR2006247.

Cadman, C.S.C., P.E. Toorop, H.W.M. Hilhorst, and W.E. Finch-Savage. 2006. Gene expression profiles of Arabidopsis Cvi seed during cycling through dormant and non-dormant states indicate a common underlying dormancy control mechanism. Plant J. 46:805-822, doi: 10.1111/j.1365-313X.2006.02738.x.

Carvalho, M.L.M., R.A. Alves, and L. Magda de Oliveira. 2010. Radiographic analysis in caster bean seeds (Ricinus communis L.). Rev. Bras. Sementes 32:170-175, doi: 10.1590/S010131222010000100019 .

Esau, K. 1965. Plant anatomy. John Wiley \& Sons, Inc., New York.

Huang, S.-Q., Y. Takahashi, and A. Dafni. 2002. Why does the flower stalk of Pulsatilla cernua (Ranunculaceae) bent during anthesis? Amer. J. Bot. 89:1599-1603, doi: 10.3732/ajb.89.10.1599.

IBM Corp, 2011. IBM SPSS Statistics for Windows, version 20.0. Armonk, IBM Corp., NY.

Kim, J.H., K.O. Kim, A.K. Lee, M.S. Roh, and J.K. Suh. 2017. Germination of Corylopsis seeds evaluated by X-ray imaging and cold stratification. Hort. Sci. (Prague) 11:105-111, doi: 10.17221/194/2015-HORTSCI.

Kim, J.H., J.K. Suh, S.-T. Yoon, P. Jourdan, and M.S. Roh. 2018. Germination of fully developed Corylopsis seeds influenced by harvest date and cold stratification. HortScience 53:1360-1363, doi: 10.21273/HORTSCI13032-18.

Nikolaeva, M.G., T.V. Daletskya, M.V. Razumova, and N.A. Askochenskaya. 1973. Effects of gibberellin and kinetin on embryo growth and seed germination in spindle tree and tatar maple. Sov. Plant Physiol. 20:600-605.

Roh, M.S., J.-A. Bentz, P. Wang, E. Li, and M. Koshioka. 2004. Maturity and temperature stratification affect the germination of Styrax japonicus seeds. J. Hort. Sci. Biotechnol. 79:645-651, doi: 10.1080/14620316.2004. 11511820

Sang, C.K., E.H. Kim, and H.Y. Kim. 1993. Germination and life span of Pulsatilla cernua var. koreana seeds. J. Kor. Soc. Hort. Sci. 34:207212. (In Korean with English summary).

Sang, C.-K., B.-J. Choi, and J.-C. Koh. 1996. Effect of storage humidity and temperature on seed germination of Pasque flower (Pulsatilla cernua var. koreana). J. Kor. Soc. Hort. Sci. 37:447450. (In Korean with English summary).

Wang, F., L.-M. Zhang, D. Zhang, X.-M. Yu, and H. Song. 2013. Effect of different treatments on seed germination of Pulsatilla turczaninovii and Pulsatilla dahurica. Northern Hort. 2:6567. (in Chinese with English abstract).

Yuan, T., Q. Wei, and G. Bauchan. 2019. Germination of Pulsatilla seeds as influenced by seed morphology, moist $5{ }^{\circ} \mathrm{C}$ and gibberellin $\left(\mathrm{GA}_{3}\right)$ treatment, and detection of nickel in seeds. HortScience 54:2015-2023, doi: 10.21273/ HORTSCI14056-19. 